\title{
Crónica del XVI coloquio de historia de Lima
}

\author{
Apuntes para su historia'
}

Yovani SOTO

Ahora más que nunca he tomado conciencia de esta tertulia que los estudiantes han desarrollado en casa del profesor Maticorena. Una tertulia con todas las dificultades de una universidad pública, una tertulia donde incluso tenía sus ventajas económicas para los alumnos (...), ahí en esta tertulia veo la influencia del maestro Raúl Porras, la tertulia de la calle Colina. Seguramente dejaron una impronta que le permitió después hacer un magisterio más allá de la universidad, como se debería hacer en otras circunstancias y en muchas universidades del mundo.

Discurso del Rector Manuel Burga en la ceremonia de incorporación de Miguel Maticorena al Profesorado Emérito.

El XVI Coloquio de Historia de Lima $^{2}$ se realizó en el Centro Cultural de San Marcos (Casona) los días 20 y 21 de enero. Auspiciado por La UNMSM, la Academia Peruana de la Historia, el Comité Peruano de Ciencias Históricas y la Asamblea Amistosa Literaria. Estuvo dedicado a la conmemoración de los 400 años de la edición de los Comentarios del Inca Garcilaso de la Vega y el aniversario de las Cortes de Cádiz. Abrió el evento el Dr. Oswaldo Holguín, miembro de la Academia de la Historia. La primera mañana estuvo dedicada a las Cortes de Cádiz. El R. P. Armando Nieto Vélez disertó sobre Fidelismo y Cortes de Cádiz. El Dr. José Agustín de la Puente Candamo sobre Las Cortes de Cádiz en el tiempo precursor de la Independencia; Samuel Villegas sobre Dionisio Túpac Yupanqui, Diputado en las Cortes y Marissa Bazán sobre Gaspar Jurado, indígena, y de Historia De Lima apareció en la Revista Histórica t. XLI (2005-2006).

${ }^{2}$ Los organizadores fueron Marcos Grafías, David Franco, Javier Saravia Yovani Soto; fueron asesorados por su fundador y principal impulsador, Miguel Maticorena. 
la igualación social de la Constitución de Cádiz. La tarde del martes 21 se dedicó a los Comentarios Reales. El Dr. Óscar Coello disertó sobre el Testimonio ficcional de la Florida del Inca Garcilaso. El Dr. Waldemar Espinoza expuso ¿Por qué Garcilaso llamó Comentarios a su obra?, El Dr. César Toro presentó una ponencia titulada Garcilaso, sabio y Amauta. Miguel Maticorena hizo un breve análisis de la ficción y la historia, en el Manuscrito inédito de la Florida, el cual actualmente investiga. Cerraron la sesión del martes la presentación de los libros: Deuda interna y externa del Perú (siglo XIX), Los orígenes de la novela castellana en el Perú. La toma del Cuzco (1539) y Garcilaso de la Vega y la Florida del Inca. La sesión del miércoles 21 estuvo dividida en las siguientes mesas temáticas: Arqueología de Lima en la Casa Museo Belén, Lima borbónica (s. XVIII), Dogmatismos políticos en Lima (s. XX), Sociedad, Diplomacia y Ciencia (s. XIX y XX), Prensa, Arquitectura y Urbanismo, y Deporte y modernización. La clausura del evento fue antecedida por la presentación de la Revista Tiempos, del investigador Juan San Martín.

Con dieciséis ininterrumpidos años de realización y gran asistencia de público, en Los Coloquios de Historia de Lima se han presentado más de 700 ponencias y se ha reunido a gran parte de la comunidad académica del país. A pesar de no contar con financiamiento económico ni institucional permanente ${ }^{3}$ y una organización básicamente docente y estudiantil. Su historia es testimonio de parte importante de la historiografía sanmarquina de los últimos veinticinco años.

Interesa saber entonces ¿Cómo se organizan? ¿A qué debe su vigencia? y ¿Cómo se proyecta en los próximos años?

\section{Fundación de los Coloquios}

Aparecen en 1993 como una iniciativa docente y estudiantil. Su objetivo inmediato fue promover la investigación histórica de Lima. En segundo lugar, construir un espacio de entrenamiento, estímulo y promoción para estudiantes con investigaciones iniciadas. Aunque no fue el único espacio de esta naturaleza en aparecer ha logrado instituirse en una amplia red de contactos. La responsabilidad de llevarlos a cabo es de estudiantes e investigadores sanmarquinos, asesorados por su fundador, Miguel Maticorena Estrada4. Ha tenido como sedes los principales centros académicos de Lima, destacando el Centro Cultural de San Marcos (Casona), el Instituto Riva Agüero (PUCP) y El Club de la Unión. Además han recibido

${ }^{3}$ Salvo el V Coloquio de Historia de Lima, financiado por Prom Perú. Aquella vez se presentaron más de cuarenta ponencias en tres días.

${ }^{4}$ Director de la EAP de Historia de la Facultad de CC.SS, de la UNMSM en 1993. la colaboración de instituciones como PromPerú, la Municipalidad de Lima, la Academia Nacional de la Historia y desde 1996, el respaldo del Comité Internacional de Ciencias Históricas $(\mathrm{CISH})^{5}$.

\section{Temas y contenidos}

Los coloquios no sólo estudian la Lima "histórica" sino también la Lima actual, en un intento multidisciplinario. El $V$ Coloquio de Historia de Lima presentó 149 ponencias, de las cuales el 7\% fueron temas arqueológicos, un $3 \%$ de temas de arquitectura ${ }^{6}$, un $7 \%$ de investigaciones sobre arte, un $6 \%$ de sociología, un $8 \%$ temas literarios y un 3\% de antropología. El resto trató sobre historia de costumbres y devociones populares. Llama la atención los apuntes sobre migraciones, multiplicación de barriadas, distritos nuevos y pueblos jóvenes preparados por historiadores. No pocos trabajos se detuvieron en la cholificacion de Lima o la transformación de la antigua ciudad virreynal en una aldea múltiple donde convergen ahora las variadas tradiciones andinas ${ }^{7}$. Desde la literatura, la nueva Lima ${ }^{8}$ fue comentada en Lima en Rock de Oswaldo Reynoso, El cielo sin cielo de Lima de Carlos Zavaleta y la Lima la horrible de Salazar Bondy. Algunas ponencias fueron ampliadas y publicadas como tesis, artículos y libros $^{9}$.

De igual modo, los coloquios contribuyeron al fomento de la vida académica, difundiendo la importancia de eventos como el II Congreso Internacional de Peruanistas en el extranjero (Sevilla-2004), y el Congreso Mundial de Historia, organizado por el CISH (2005), que estuvieron entre los pocos espacios académicos de la universidad sumados a las celebraciones mundiales por el IV Centenario de la historia de La Florida del Inca Garcilaso, el Quijote y, este año, a los 400 años de Publicación de los Comentarios Reales. Justamente una ponencia se encargó de divulgar la representación teatral del Quijote en Pausa (Ayacucho) a un año de publicado el libro en España (Coloquio No XII, 2005).

5 Fundado por Marc Bloch, padre de la Nueva Historia. Vease el Bulletin d' information del COMITÉ INTERNATIONAL DES SCIENCES HISTORIQUES. 31-2005, Montreal.

${ }^{6}$ Proyectos de restauración como la recuperación de la Casa de Ejercicios de S. Francisco Solano en el Rímac y la restauración de la Iglesia San Pedro, también exposiciones de futuros proyectos municipales como el proyecto del Parque del río Hablador y otros de renovación urbana dirigidos por Alberto Sánchez Aizcorbe, La plaza (Lorenzo Huertas), y la importante restauración de la Casona de San Marcos por la Misión Cultural de España a cargo del Arquitecto Juan la Serna.

7 Pero como señalaran en su momento Jaime Ríos Burga y otros ponentes, desbordaron la capacidad de la ciudad, generando caos, desorden y un nuevo tipo de cultura urbana.

${ }^{8}$ Mariana Mould, en una oportunidad, recordó al catedrático sanmarquino Bruno Rosselli y sus balcones. Como es sabido Vargas Llosa perennizó la memoria de Bruno Rosselli en la obra de teatro El loco de los Balcones.

${ }^{9}$ Luís Sifuentes. Las Murallas de Lima, editado por el Congreso de la Republica y los artículos de Kroski Alvarado sobre camaroneros son una pequeña muestro de ello. 


\section{Espacio de difusión}

Las sesiones permitieron cultivar amistades académicas que enriquecieron teórica o metodológicamente algunas ponencias (recomendando su publicación cuando ameritó), permitiendo mantener también "alguna actualidad bibliografica": francesa, española, mexicana, chilena, paraguaya, norteamericana y hasta japonesa ${ }^{10}$. Como evidencia, la presentación de la tercera edición de la Crónica Summa y Narración de los Incas de Juan de Betanzos, preparada por María del Carmen Martín Rubio o la monografía de Juan Villarías Reyes Incas y épocas del Perú Prehispánico, enviada al Comité Organizador por el Consejo Superior de Investigaciones Científicas de Madrid. En el ámbito nacional se dio noticia de libros o revistas entonces recién publicados, como fueron Caudillos y Constituciones de Cristóbal Aljovín, La nobleza de Lima de Paúl Rizo Patrón, El Mercurio Peruano de JeanPierre Clement o Cuadernos de Piuranidad de José Estrada Morales. También hay que mencionar la Historia de Comas de Santiago Tacunán y la reedición de La Iniciación de la República comentada por Cesar Puerta y Javier Pérez, El Origen de los Símbolos Patrios de Marcos Garfias, Efigenia, la negra Santa de Julio Luna y Tiempos de carnaval, escrito por Rolando Rojas.

La Revista Summa Historiae fue presentada por sus editores y nóveles americanistas, Richard Chuhue y Juan José Heredia, en el XII Coloquio (2005). Anteriormente fueron presentados algunos números de Nueva Síntesis, la Revista de Investigaciones Sociales de la Facultad y el primer numero de Diálogos en la Historia de Walter Vega y José Chaupis, igual la revista Albatros, la revista Perú Contemporáneo editada por Marco Garfias, el segundo numero de Uku Pacha de Juan J. Pacheco y Dino León. También se presentaron los primeros números de Historia Total, Perspectivas y la Revista Tiempos.

\section{Memoria histórica}

Los coloquios mantienen viva la memoria de obras y personajes vinculados a la historiografía peruana y sanmarquina, a pesar de que a partir 1993 funciona en la facultad una cátedra sobre la Historia de la Universidad" ${ }^{1}$.

\footnotetext{
io Sosho Mazuda, de la Universidad de Tokio, disertó sobre los Contactos entre Japón y América, siglo XVII. "Se recordaron por ejemplo a Luis Codin matemático y astrónomo francés, profesor de matemáticas de San Marcos, quien trazó el plano de las murallas y sus informes sobre el Callao después del terremoto de 1746; Juan Bromley Seminario, editor de los libros de Cabildo de Lima y autor de la Fundación de la Ciudad de los Reyes (1935); Don Alejandro Lostaunau Ulloa, organizador y fundador de la biblioteca del Instituto Riva Agüero; José Gálvez y sus Calles de Lima y meses del año (1943); Luis Antonio Eguiguren por Calles de Lima (1945) y sus aún no superados trabajos sobre la historia colonial de San Marcos; Raúl Porras por su Antología de Lima publicada en 1935; Ella Dumbar Temple y sus trabajos sobre beatas, iluminadas, teatro y la Universidad San Marcos a fines de la colonia. Respecto a la Cátedra de Historia de San Marcos, véase el trabajo de Miguel Maticorena: San Marcos de Lima Universidad Decana de América. Una Argumentación Histórico-Jurídica y el Derecho Indiano. Fondo Editorial UNMSM. 2000.
}

Tal es el caso de Guillermo Lohmann Villena (1915-2005), diplomático e historiador matriculado en la Facultad de Letras de San Marcos (24 de abril de 1941), profesor de "Historia de la Cultura Española" en la misma Universidad a petición del Dr. Carlos D. Valcárcel. Luego fue ratificado por Raúl Porras Barrenechea, entonces director del Instituto de Historia (Junio 11 de 1951). Otro caso es el de Carlos Lazo ${ }^{12}$ historiador y catedrático sanmarquino, especialista en Historia Económica y Monetaria, autor de Economía colonial y régimen monetario del Perú s. XVI-XIX en 3 tomos (1992). El total de la obra historiográfica de Carlos Lazo espera todavía justo balance.

\section{Organización y funcionamiento}

El comité organizador no se ha institucionalizado. Es más bien una comunidad cuyo común denominador es la amistad, el magisterio del profesor Miguel Maticorena y el interés por la investigación. Las reuniones se realizan en su casa y el contacto con los ponentes más importantes es a través de su teléfono y su prestigio. Ahí llegan periódicamente las novedades bibliográficas y las invitaciones para actos académicos dirigidos al profesor, permitiendo a la organización tener un panorama del ambiente académico de la ciudad, pero sobre todo acceso a él.

El pago de programas y afiches ha sido cubierto por San Marcos contadas veces, aunque figura como auspiciador en todas sus versiones. Gracias al profesor y la trayectoria del evento, se consiguen los locales y los equipos sin ningún tipo de alquiler ni engorroso trámite burocrático.

No existe ninguna compilación de ponencias publicada, salvo una de resúmenes, pero sí una colección completa de programas y algunas ponencias grabadas, pero sobre todo un importante archivo fotográfico. Juntos permiten ver algo de las tendencias temáticas (variaciones y continuidades) $)^{13}$.

La recepción de ponencias no es abierta, más bien "selectiva". Graduados e investigadores son invitados por la organización o se ofrecen. Este mecanismo es uno de los pocos medios para contactar a la comunidad estudiantil de la Escuela con algunos de sus egresados y los peruanistas de paso. Por el contrario, los estudiantes ponentes son contactados por los organizadores a través de sus jefaturas de práctica u otra actividad académica en la universidad.

${ }^{12}$ Su tesis Introducción al estudio de la crónica de denuncia social virreinal (1975) en: Praxis en la Historia. № 3-2004.

${ }^{13}$ Yovani Soto Villanueva. Doce años de Coloquios de Historia de Lima. En: Revista Histórica. Tomo XLII. Lima 2005-2006. Incluye índice de títulos. 
Más o menos entre 1993 y 1999 participaban estudiantes con investigaciones avanzadas, incluso con publicaciones previas. A partir del 2000 éstas disminuyeron notoriamente. En estos casos Maticorena sugirió temas que terminaron como artículos, tesis o libros; iniciándolos secretamente a la investigación, redacción y la disertación ${ }^{14}$ historiográfica, actualmente una práctica totalmente ajena a la currícula universitaria de la Escuela.

La asistencia del público ha sido permanente, pero irregular en cantidad y composición. Esto está relacionado con la poca y tardía difusión de los programas y los afiches del evento; primero, por la falta de apoyo institucional; y segundo, porque no se ha modernizado la organización.

\section{Proyecto de investigación}

Sin el reconocimiento ni apoyo de la Escuela, los Coloquios de Lima han difundido y auspiciado gran parte de su investigación. Durante dieciséis años ha invitado a casi toda la plana docente de la Escuela de Historia de San Marcos. Entonces ¿Por qué no incorporar los Coloquios de Historia de Lima y asumir su realización?

Urge aprovechar el potencial académico del evento para reforzar la pobre vida académica de la escuela de Historia de la UNMSM, aprovechando la amplia red de contactos que ha logrado, para vincularse al mundo de las becas y financiamiento internacional de proyectos de investigación ${ }^{15}$.

¿Una generación historiográfica? Como señalamos, los coloquios exhumaron una serie de temas y fuentes para la historia de Lima, mientras se constituía un espacio de entrenamiento y promoción para un grupo de historiadores sanmarquinos. Como evidencia el artículo de Francisco Quiroz sobre la historiografía joven peruana (1987-1995), ${ }^{16}$ los Coloquios permitieron, en algunos casos, la exposición de avances que luego difundirían en otros coloquios, congresos, artículos o acabarían en tesis ${ }^{17}$. Según Quiroz se caracterizan por "tener una variada metodología,

\footnotetext{
${ }_{14}$ Para razonar, discurrir detenida y metódicamente sobre alguna materia, bien para exponerla, bien para refutar opiniones ajenas.

${ }^{15}$ Ante el boom culinario y cultural presente, significaría un puente entre la investigación universitaria y la iniciativa empresarial. Como ha sabido hacer la PUCP con su Instituto de Estudios Orientales y la Universidad San Martín con sus investigaciones y publicaciones sobre culinaria nacional.

${ }^{16}$ Francisco Quiroz. “La Historiografía joven peruana 1987-1995”. Diálogos en la Historia, No 1, 1999. ${ }_{17}$ Cuando Juvenal Luque disertaba sobre La Caja Real de la Hacienda de Lima en el I coloquio de Historia de Lima (1993) ya tenía publicaciones sobre reducciones salariales de la burocracia limeña (1992), sobre arbitrios técnicos de minería colonial (1986) y el precio tributario del oro colonial (1993). En el mismo Coloquio Luis Arana hablaba de la "Casa Real de la Hacienda de Lima" teniendo publicados artículos sobre "legislación monetaria colonial" (1991), "acuñación monetaria colonial" (1991) y "crecimiento economico del Perú del siglo XVIII" (1993). En 1994 Héctor Maldonado disertaba sobre las "Cajas de comunidad en el II Coloquio para después publicar en la Revista Sequilao El juzgado
}

diferentes condiciones e intereses de investigación, de desarrollo profesional y apego a modas externas". Resultando así una "generación" con producción heterogénea, sin enfoques que vinculen los "problemas aislados que estudian" al proceso histórico general, aunque valora mucho su trabajo con información documental verificada y su riguroso análisis.

Pero una "generación de historiadores" no sólo es un conjunto de individuos que "reflexionan" de manera comparable sobre ciertos temas, sino que sus afinidades teóricas y metodológicas coinciden en una explicación particular de su sociedad ${ }^{18}$, de tal modo que el término "generación" todavía no puede englobar el conjunto de ponentes sino en un sentido operativo, porque priman estudios de problemas sin enfoque de conjunto, además de las otras características señaladas (Quiroz: 1999). La revisión de los títulos de las ponencias presentadas en los Coloquios evidencia lo mismo ${ }^{19}$.

¿Cambios o continuidades? No nos interesa hacer un balance cualitativo de esta historiografía. Procuramos llamar la atención sobre una de las características de su formación actual, que junto a otros factores, impiden que la Historia, desde San Marcos, contribuya al análisis de la compleja problemática actual ${ }^{20}$, así como a su perfeccionamiento profesional y económico. Toso esto sin desmerecer los invalorables aportes que siguen brindando los investigadores mencionados y del que son testimonio los Coloquios de Historia de Lima.

Esta característica la recoge Mario Mesa en un detallado estudio inédito sobre las imágenes y realidades de la profesión en San Marcos ${ }^{21}$. Ahí pone en evidencia la relación que existe entre las condiciones institucionales de la facultad y el tipo de formación que ofrece.

Mesa señala que la idea que tienen los estudiantes de la práctica profesional, así como la elección de los temas de investigación y la metodología, e incluso las vías de financiamiento y publicación; son tomadas -en muchos

general de la caja de censos: una institución financiera colonial. Un caso similar es el de Maribel Arrelucea, que en el IV Coloquio (1996) presentaba una investigación sobre panaderías coloniales que acabaría publicando el mismo año en la Revista del AGN como Conducta y control social colonial. Estudio de las panaderías limeñas en el siglo XVIII. Podríamos citar más ejemplos.

${ }^{18}$ Los Historiadores Marxistas Británicos. Un análisis introductorio. Edición y presentación de Julián Casanova. Universidad de Zaragoza, 1989.

19 Yovani Soto Villanueva. Doce años de Coloquios de Historia de Lima. En: Revista Histórica. Tomo XLII. Lima 2005-2006. Incluye una clasificación de los títulos presentados.

${ }^{20} \mathrm{El}$ historiador analiza y explica los hechos sociales, económicos, políticos e ideológicos, acaecidos en las sociedades para entender el presente y planificar el futuro. Véase el perfil profesional de la carrera de Historia que aparece en los Prospectos para preuniversitarios.

${ }^{21}$ Mario Mesa. Ser historiador: imágenes y realidades de una profesión en el escenario estudiantil de la UNMSM. En Prensa. 
casos- de experiencias profesionales individuales. Como por ejemplo las de Carlos Lazo, Waldemar Espinoza, Miguel Maticorena, Francisco Quiroz. Y no de un plan curricular orgánico.

El historiador graduado es resultado de la propia selección de modelos y experiencias profesionales basadas en referentes individuales. La currícula, el perfil profesional y por extensión la Escuela Profesional de Historia están divorciados de los espacios institucionales (estatales o privados), de potencial ocupación laboral. Estos vacíos dejan entonces vía libre para las iniciativas particulares, como son los conversatorios, coloquios y revistas estudiantiles.

Esta situación se ha venido agravando en los últimos veinte años. En su evaluación del año académico de 1988, Manuel Burga, entonces director de la Escuela de Historia, llamaba la atención sobre los factores estructurales que podían hacer colapsar la universidad: el empobrecimiento de la formación científico-académica docente y la ausencia de vida institucional. Concluye Burga que "el futuro inmediato de la Escuela de Historia no es promisorio y difícilmente podrá invertirse la tendencia hacia el deterioro creciente de las actividades académicas e institucionales". ${ }^{22}$

El valor de los Coloquios reside precisamente en reunir, promover y estimular parte de esta historiografía que insiste en seguir investigando a pesar de los problemas ${ }^{23}$. Ambos son testimonio de cómo la Universidad (al no fomentar la excelencia académica entre los estudiantes, por el contrario, los abandona) estimula en los que persisten, la autodisciplina, la autodidáctica y la iniciativa necesaria para buscar por otros medios lo que la universidad no les da.

\footnotetext{
22 Boletín Informativo No 2. EAP de Historia. Universidad Nacional Mayor de San Marcos. Facultad de CC.SS. Lima 1989.

${ }^{23}$ Los Coloquios de Historia de Lima todavía no son abiertos. El Comité Organizador invita a estudiantes y egresados con avances de investigación o publicaciones.
}

\section{INSTRUCCIONESA LOSAUTORES PARA DESDE EL SUR}

\author{
1. Se tratará temas relacionados con la investigación en todas las áreas de \\ ciencias humanas y ciencias sociales. \\ 2. Los trabajos deben ser originales e inéditos. \\ 3. Pueden ser redactados en cualquier lengua. \\ 4. Los textos recibidos serán arbitrados anónimamente por dos expertos \\ de la especialidad o campo de estudio, antes de ser publicados. Nuestro \\ sistema de arbitraje recurre a evaluadores externos a la Universidad \\ Científica del Sur.
}

5. Debe enviarse dos ejemplares impresos en papel bond blanco A4, en una sola cara, a doble espacio, con márgenes a los costados de $3 \mathrm{~cm}$., con una copia al correo institucional.

6. El texto debe ser entregado, también, en soporte digital (en CD) en programa Word para Windows 97/2000 o XP. El tipo de letra es Arial, tamaño de fuente 12 .

7. Si el texto incluye gráficos o figuras debe ser estar en formato TIFF a una resolución mayor de $500 \mathrm{dpi}$. Se considera figuras a los dibujos, mapas, fotografías o gráficos, ordenados con números arábigos, en el caso de que sean fotografías convencionales o dibujos. En la parte posterior de cada una se debe anotar su número, ubicándolo arriba y a la derecha, así como el autor y el título del artículo.

8. Los textos deben presentar el siguiente orden:

a) Título del artículo. El título del artículo debe ser corto y claro. Debe estar en castellano e inglés.

b) Nombre del autor o autores: apellidos, nombres, filiación institucional y correo electrónico.

c) Resúmenes en dos lenguas: español e inglés (incluyendo, a continuación de cada resumen, palabras claves en las respectivas lenguas). 